\title{
A New Perspective of Staff Encouragement: Review on Psychological Territoriality
}

\author{
Qiang Zhao, Wen-Quan Ling \\ School of Management, Jinan University, Guangzhou, China \\ Email: Ifzhaoqiang@126.com, tlwq@inu.edu.cn
}

Received 25 October 2014; revised 26 November 2014; accepted 2 December 2014

Copyright (C) 2014 by authors and Scientific Research Publishing Inc.

This work is licensed under the Creative Commons Attribution International License (CC BY).

http://creativecommons.org/licenses/by/4.0/

(c) (i) Open Access

\begin{abstract}
Employee psychological territoriality has become one of the emerging fields of the western organizational behavior research in recent years. However, there are very few related studies in the domestic research. This paper at first reviewed and analyzed the main theoretical literature and the latest empirical research on employee psychological territoriality at home and abroad in order to explore in depth Employee psychological territoriality's definition, composition and its antecedent variables and result variables. Finally, based on the overview of previous studies, some managerial suggestions were made and directions for future research were prospected.
\end{abstract}

\section{Keywords}

Staff Encouragement, Psychological Territoriality, Territorial Behavior, Psychological Ownership

\section{Introduction}

Under the current subversion of traditional industries and the frequent changes in the organizational context of the Internet, the working environment is full of uncertainties. The organizations for competitive advantage and shared Internet dividends, such as streamlining personnel, outsourcing, restructuring, mergers and acquisitions, plant closings, etc., are often reform measures adopted [1]. So it makes many employees feel job insecurity. "Nokia's decline", "Haier's self-revolution" and the company's transformation undoubtedly explain the reason why the temporary employees face increasing work pressure. This pressure will produce a lot of negative impacts on organizational performance and employee production.

American economist Robbins pointed out that "human capital value = work ethic + the ability to work". Lack of employee enthusiasm will directly lead to business investment in human capital which can't be maximized. Under the new competitive situation, how to effectively motivate employees, retain talented employees and improve work performance of employees has become a key issue to achieve sustainable development which each 
enterprise must face. Increased competitive pressures force companies to seek more effective ways to nurture and develop a harmonious relationship between employees and the organizations of various acts of employees, such as voice behavior, counter-productive behavior, silent behavior and deviant behavior, which have attracted more and more researchers' attention. Currently, responsibility and stable remuneration have not become major driving forces behind the work of the staff dutifully [2]; changes in the concept of employee incentives also require companies to be adjusted accordingly. Among them, territory of psychological theory provides a new perspective on how to motivate employees, from the aspect of content and theoretical foundation, structure, antecedents, effects, etc. The results of the main theories of psychological literature on the territory of employees abroad and the latest empirical research review propose relevant management revelation on the basis of previous studies reviewed, and provide new research perspective for future research.

\section{Connotation and Theoretical Basis of Employees' Psychological Territoriality}

Territoriality of originated in animal studies refers to the protection of Territoriality possession and animal behavior [3]. In the $1970 \mathrm{~s}$, some scholars have found that the behavior is actually a Territoriality organization of human behavior [4], and the territoriality within the organization will also help organizations avoid sexual violence inside unnecessary. Until 2005, Territoriality was formally introduced the notion of the field of organizational behavior [5], research also extends the range of behavior from territoriality to territoriality acts of physical space under the organizational context of social object, that concern the organization psychological Territoriality of employees.

In organizations, the psychological territoriality of employees is very common, often can be observed employees exhibit the following behaviors: personalized items placed in the workplace to decorate an office environment; use locks to prevent others from entering his office; efforts to control own information, the use of certain electronic document password protection; for those in charge of other employees to intervene in their own projects exhibited hostility; reluctant to share their own interpersonal networks, and so on.

\subsection{Definition of Employee Psychological Territoriality}

With the ethos of social freedom advocate, employee self mentality more obvious, when the physical distance between approximation to a little distance, there will be vigilance, wants defense their territory belongs to a particular space or staff psychological territoriality the concept of response for us. Study found that people are born with a territory of [6]. Brown et al. (2005) expanded the organization to define the boundaries of the territory, which is defined as an individual to express a sense of belonging or ownership of an entity or social objectives of behavior [5]. They think that sexual territory has two components, namely a sense of territory and territorial behavior point to the target. Among them, the territory of employees feel a sense of ownership of the means of many target tissues produce, such as sense of ownership of the office, role and perspectives; the territory is to establish employee behavior exhibited by these goals, communicate or control their relationship with these objectives behavior. When the individual will be regarded as something of all things, it will show the territories behavior to establish, communicate and maintain their territories [7]. Subsequently, Brown and Robinson (2010) continue to improve the territory of the concept, noting the psychological territoriality of employees in the organization of work and life in general has a psychological sense is a personal sense of ownership of the object, and to prevent others from approaching or possession consciousness [8]. However, Brown and Robinson generals to sexual limited to "acts of expression" narrow approach of the territory of employees' psychological connotations, Chinese scholars Peng He further development the meaning of territory, furthermore he distinguish the territory and territorial behavior of these two concepts, he said territory refers to an individual or group to protect territory infringement psychological tendencies; territorial behavior refers to the territory of the relevant individuals or groups engaged in various actions, and its purpose is to advocate, declared, maintain consolidate, protect and expand their control rights on the territory [9].

In summary, the staff refers to staff psychological territoriality sense of ownership of the object in the organization of work, and protect it from infringement of psychological tendencies. It should include three elements: (1) employees territory cognition, referring to employees who should enter a territory, a territory who should care and what activities are allowed in certain territories, etc. perception or belief; (2) employees emotional territory, referring to employees associated with the territory and the territory of emotional connection between the characters, both with the territory to maintain positive emotions, but also includes the territory of the violation when 
the negative emotion may be triggered; (3) employees territorial behavior, referring to efforts to protect the territory of employees infringement behavior.

\subsection{Theoretical Basis of Employees' Psychological Territoriality}

What are the root causes of employee psychological territoriality of that? Employees should feel the object of all their standards, what is it? This requires from the theoretical basis of employees' psychological territoriality to think.

First, look at the nature of the employment relationship, employment contracts between employers and employees is an incomplete contract. Thus, the employee stock ownership plan began to be used to motivate employees to ownership and attitude into business management. Later, Pierce, Linn and Tatiana introduced the concept of psychological ownership of this new reality to re-examine the relationship between ownership, work attitude and work behavior among employees, territory behavior caused by psychological ownership is also beginning to receive attention [10].

Secondly, we can see from the territory of the psychological connotations, psychological ownership is the root cause of employee psychological territoriality; psychological territoriality of psychological ownership is based on the above. Psychological ownership is a necessary condition for the implementation of territory behavior of employees, and achieving psychological territoriality of psychological ownership by marking and defensive behavior. They have two differences: (1) the psychological territoriality of the expression of the "this is mine" and "it's not yours", and psychological ownership expressed only "this is mine"; (2) psychological territoriality of which the organization and employee scenarios are closely linked, but the heart of ownership reflects only a state of mind, can exist independently of the organization scenarios.

\section{The Structure of Employee's Psychological Territoriality}

Currently, on the territory of employee psychological classification requires in-depth discussion. Based on the scenario organization classified by Brown, Lawrence and Robinson (2005) suggested that they put psychological ownership as the psychological basis of territory within the organization. And they believe that the individual's perception of psychological ownership acts of physical or social object of expression, in fact, can be divided into two categories mark and defense.

Mark refers to members of the specific organization objects built into the territory of their own territory and inform the actions of others. Mainly includes two types of tags: identity-oriented marking and control-oriented marking. Identity refers to the individual intentionally guide markers decorated surroundings amended to reflect the behavior of its identity; its function is to transfer their properties to others through such markers, build a personal territory. Control refers to the individual's objectives guide markers do can react territory boundaries and who hold this territory mark of ownership, its role is to communicate with others, to inform others, this territory has been argued that in order to prevent others from entering, use and destruction, to achieve the purpose of declaring the territory.

Defense, including two forms of anticipatory defenses and reactionary defenses, mainly used to maintain territories and remodeling territory. Anticipatory defense prior to the violations, referring to the territory before being used in violation of the individual to discourage the behavior of others to invade targeted mainly rely insurmountable hard to establish some boundaries (such as sturdy steel doors or with armed security). Reactive defense after violations, referring to the territory after being violated in order to deter violations and rebuild areas targeted behavior of individual use, mainly rely on meaningful and obvious social markers (such as eyecatching lock flag).

\section{Territory of Employees' Psychological Factors}

Employee psychological territoriality is a very common phenomenon in the organization, but the current research related to employees' psychological factors of the territory is very weak and mostly still in the theoretical stage.

Throughout the previous studies, the impact of employees' psychological territoriality includes two categories of individual and organizational factors. Specific path is shown in Figure 1. 


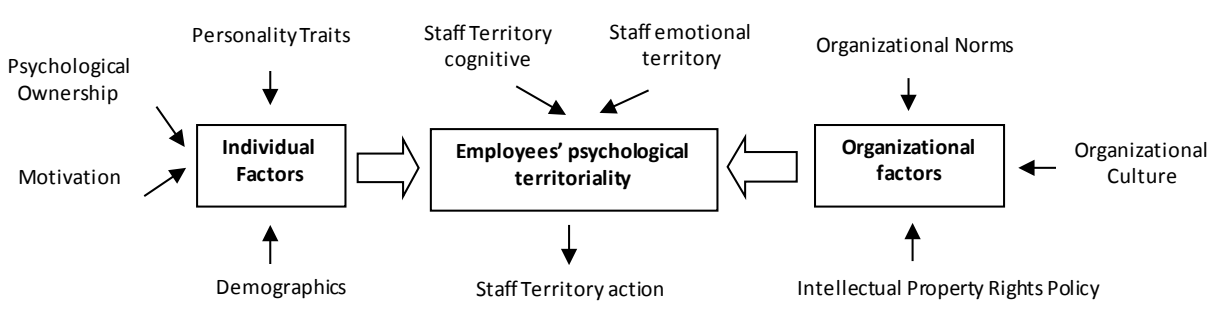

Figure 1. Territory of employees' psychological factors.

\subsection{Individual Factors}

\subsubsection{Demographics (Individual Gender)}

Differences in employees' psychological territoriality of gender have a great relationship with the staff, while in other demographic characteristics did not show significant differences, most of the existing research shows that more men than women have a stronger psychological territoriality. Findings of Mercer and Benjamin (1980) on the marked area showed that the area of their own subjects was marked men than women [11]. Because men tend to occupy higher positions than women, and therefore will usually require a larger working space, Mercer and Benjamin after exclusion of posts factors, the results also show that male students have a stronger territorial nature. But there are empirical studies showing that in the office of personalization on gender differences, women more than men degree of personalization and personalization reasons men and women are different [12].

\subsubsection{Motivation}

Stimulate intrinsic motivation refers to the driving force of employees' psychological territoriality. Chu and Ni (2009) argue that affect employees' psychological territoriality of motivation comes mainly from four aspects: the need for achievement, self-space needs, self-identity and self-efficacy needs [13]. The more intense motivation of employees, that need for achievement, self-space needs, self-identity and self-efficacy requires more intense, then the psychological territoriality higher.

\subsubsection{Personality Traits (Individual Control Point)}

Psychologist Rotter (1966) makes the low controllability of the individual called "internal model", the higher called "foreign-controlled". Chu and $\mathrm{Ni}$ (2009) argue that territoriality is inversely proportional to their psychological relationship between the individual control points, namely the lower control point of the individual, but the psychological territoriality the higher [13]. In the context of similar organizations, internal control workers are more inclined to believe that they can produce on the consequences of behavior and take action to control the developments, but these often require appropriate support resources, internal control based access to resources needed for it than the external control workers more prone territoriality behavior.

\subsubsection{Psychological Ownership}

Psychological ownership is the theoretical basis of psychological territoriality, which is believed by many scholars to be the most direct influence employees' psychological territoriality the factors. Brown, Lawrence and Robinson (2005) believe that psychological ownership is an important pre-variable territoriality behavior. Employee ownership of the target, the stronger the hold of the heart indicates that the target of the psychological sense of the greater value of staff, in order to protect their psychological territoriality the target will be higher. Jarvenpaa and Tanriverdi (2006) used the experimental method to manipulate psychological ownership, and found that psychological ownership and identity tags and control-oriented guide marks were showing significant positive correlation [14]. Brown (2009) verifies the relationship between psychological ownership and behavior among the four territoriality with a simple empirical research data, and the results show the psychological territoriality ownership and has a positive control, a correlation coefficient of 0.37 [7].

\subsection{Organizational Factors}

\subsubsection{Organizational Norms}

Organizational norms of behavior standards and guidelines for each member organization formed consciously abide by; its employees have a strong binding can regulate employee behavior. Chu and Ni (2009) argues that 
organizational norms for employee psychological territoriality influential role of shared organizational norms can reduce the psychological territoriality employees [13]. Shared organizational norms will help strengthen the company's internal cohesion, so that employees realize that they jointly held with the company target of psychological ownership, thereby reducing the corresponding territoriality behavior.

\subsubsection{Organizational Culture}

Organizational culture refers to a common value system of organization members; it will also affect the degree of psychological territoriality of employees. Chu and $\mathrm{Ni}$ (2009) argue that shared organizational culture can reduce the psychological territoriality employees. Stressed the organization and employees are one of the organization's culture [13] to promote unity within the organization, thereby promoting employee behavior to reduce the negative territory.

\subsubsection{Intellectual Property Rights Policy}

Intellectual property rights, such as the reality of organizational policies also affect the psychological territoriality employees. Jarvenpaa and Tanriverdi (2006) organized jointly that owned intellectual property policy was divided into two unique organizations and organizations with employees [14], and the experimental study of the impact of these two intellectual property policy staff reactive defensive behavior, and found the organization and employees together All intellectual property rights policy, resulting in fewer negative emotions, because it will bring fewer employees to organize reactive defensive behavior.

In summary, the current principal investigator from the individual level and organizational level examine the factors of employees' psychological territoriality. Among them, the discussion of individual factors are more focused on demographic characteristics, motivation, personality traits and psychological ownership, and the study of organizational factors are less focused on the organizational norms, organizational culture and organizational rights policy in three areas. Visible, coming on individual variables, the relationship between organizational variables psychological territoriality of employees also need more research and further empirical verification.

\section{The Impact Effect of Employees' Psychological Territoriality}

The study found that the staff has a very complex psychological territoriality impact on individuals, teams and organizations as Figure 2. On the one hand, the psychological territoriality life for employees and exchanges has a positive effect, but on the other hand, the negative impact the potential employee psychological territoriality but can't be ignored.

\subsection{The Positive Impact}

From a personal perspective, the psychological territoriality employees can increase employee job satisfaction and well-being [12], through the offices of personalized adjustment or decoration, will increase employee job

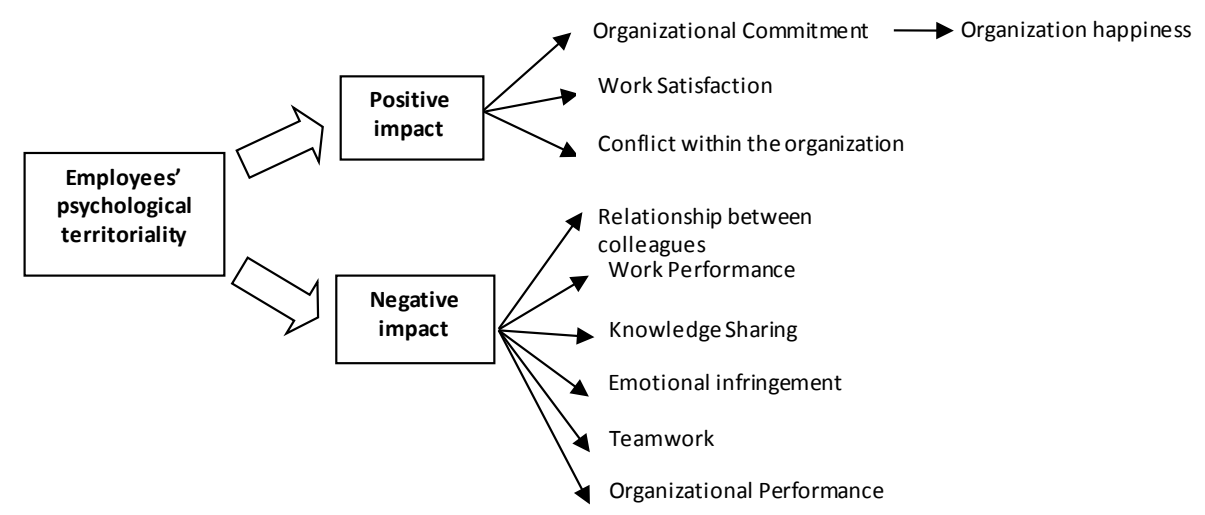

Figure 2. Employees’ psychological territoriality impact renderings. 
satisfaction, and happiness play an indirect role, the organization's policies relating to the office of personalized and organization happiness significant correlation. Employees may also bring psychological territoriality a sense of belonging [15] for employees, members of the organization to increase the level of commitment [5].

From the organizational perspective, the staff will help reduce psychological territoriality organization's internal conflict. When marking behavior or if it involves building a society agreed territory, is likely to reduce the "process of conflict" between members [16] [17]. Reduction in the organization of these "process conflict" mainly in order to boost morale [18] improves organizational performance and increased productivity. Brown, Robinson and Lawrence (2005) also believe that when an organization when employees build and maintain their own territory, territoriality behavior helps to reduce conflict.

\subsection{The Negative Impact}

From a personal perspective, the employees' psychological territoriality could result in overly obsessed with creating self-territory and colleagues with the surrounding environment causing alienation, lower job performance [5]. Psychological territoriality employees and employee knowledge conservative significant positive correlation [19], it might hinder knowledge sharing [20] and cooperation and joint efforts of the organization's goals to challenge [21]. In addition, damage property violations territoriality sense of attachment of staff, sense of control, resulting in such frustration, fear, sadness, anger, and a series of adverse consequences. Brown and Robinson (2011) on the territory of violations using the open-ended questionnaire to study and found that encroachment caused anger and extent of violations was positively correlated.

From a team perspective, employees will cause psychological territoriality estrangement and conflict between teams. Employees are often multi-territoriality considered to be difficult to work with the team, too high may lead to psychological territoriality team members to take is not conducive to knowledge sharing and team behavior. Empirical study of Chu and Yang (2011) found that employees with psychological territoriality staff team to the effectiveness of the exchange and the group were significantly negatively correlated [22].

From the organizational perspective, the senior management staff of the same have the psychological territoriality, excessive psychological territoriality political atmosphere within the organization may trigger the generation, thus causing a devastating impact on organizational performance [9].

In summary, the staff of the psychological territoriality positive and negative impacts exist, psychological territoriality for the fledgling research, the research on employee psychological territoriality consequences variables will be the most valuable research directions for the organization to function effectively it manage employee behavior, practical work to stimulate the enthusiasm of employees to provide guidance, so future research is necessary to explore the psychological impact of the effect of employees from the territoriality individual, team and organizational levels.

\section{The Revelation of Employees' Psychological Territoriality in Human Resource Management}

Research on employees' psychological territoriality of these years, you can see the psychological territoriality the staff is very common and important organizational phenomenon, is predicting employee attitudes and behaviors important psychological variables, based on the theory of psychological territoriality of the staff will greatly enrich positive organizational behavior theory of development, and management practices for managing employee incentive to provide new ideas.

\subsection{The Key of Motivation and the Purpose}

How to motivate staff motivation is one of the corporate management of human resources issues of most concern, but currently many companies put a lot of manpower and financial resources, still can't achieve the desired incentive targets. This is because the traditional pay more attention to employee motivation research positions based on short-term incentives concern, dependent systems and norms, some of the key factors often ignored incentives, such as the neglect of the power of self-motivation of employees, without considering the needs of employees differentiation, ignore the daily participation, listening, caring, encouragement and trust in the role, and so on.

Currently, human resource management has evolved from the traditional personnel management to strategic 
human resource management, paying more attention to human resources, the important role of organizational development of human capital investment. As we all know, any organization to develop and implement strategies are needed to support the attitudes and behaviors of employees. However, the traditional employee incentive management is more concerned about the work of the staff of dominant behavior, ignoring the concerns of employees and analysis of psychological factors, rarely from the staff to examine and excavate the psychological roots of staff motivation and performance.

In fact, an effective incentive system should be at the core of its own staff, to meet the different needs of employees, and actively guide the behavior of employees. This requires us to focus on what needs exist employees can motivate what direction to increase the staff's enthusiasm and satisfaction, and thus enhance organizational performance. Based on the territoriality of employees' psychological provide us with such a new idea, let's start from the psychological experience of the staff to analyze specific employees working attitude and behavior, predict job performance of employees, and then by encouraging positive behaviors and avoid negative sexual behavior to provide job performance.

Therefore, the future of incentives must depart from the psychological needs of staff, attention to guide employee behavior. Enterprises should combine their development needs and the actual situation of employees, and establish a psychological territoriality employees based employee incentive model, and actively encourage their employees to psychological territoriality, inspire staff enthusiasm and sense of ownership, improve employee job performance, promoting harmonious sound development of enterprises and employee relations.

\subsection{Based on Employees' Psychological Territory of the Incentive System}

Employees can improve psychological territoriality job satisfaction and organizational commitment levels, and help reduce the organization's internal conflict. In organizations, employees' psychological territoriality phenomenon is widespread; companies should pay close attention to employees' attitudes and behaviors spontaneously, allowing employees to conduct some favorable territoriality, as far as possible to meet the psychological needs of employees. Meanwhile, the employee psychological territoriality is also likely to adversely affect the organization, especially in terms of knowledge sharing and teamwork, companies must close communication with employees and to create and maintain an environment conducive to encourage their employees to psychological territoriality of the working environment, to ensure that employee behavior and organizational goals coincide.

Staff is an important psychological territoriality psychological experience and psychological variables, companies can build a new model based on employees' psychological motivation of territoriality, to build self-motivation in favor of staff incentive system. Therefore, the proposed combination of employee psychological territoriality the "four-force model employee incentive" to improve the practice of enterprise level employee incentive management.

Three professors at Harvard Business School-Nohria, Groysberg and Lee (2008) pointed out that there were four basic human emotional needs or driving forces: acquire needs, bond needs, comprehend needs and defend needs. These four driving force is the foundation of all our actions, companies want to motivate employees, we must try to meet them [23]. Based on the theory of psychological territoriality, through job design, a series of human resource management training and development, job promotion, career development to guide employees psychological territoriality, so as to enhance the overall perception of employee motivation levels: for the acquisition needs, organizations should focus on employee satisfaction social status, focusing on internal promotion and career development planning, through various forms of training programs, career advancement opportunities to enhance self-efficacy employees; the need for a binding, you can cultivate mutual trust between employees, pay attention collaboration and teamwork, encourage the sharing of work atmosphere and culture, in order to avoid excessive psychological territoriality the staff; for the understanding of the requirements, you can work to design and appropriate decentralization and authorization to increase the sense of control employees work and autonomy further stimulate their level of job satisfaction and organizational commitment; for defense needs, reflecting fairness and transparency in the award, selected tasks and other forms of recognition by increasing employees' right to participate in the personal development and organizational development are closely linked, thereby reducing the resistance, establish a trust relationship.

\section{Employee Psychological Territory of Prospect}

Psychological research staff territory enriched maturing psychological research ownership is gradually becom- 
ing a new hotspot organizational behavior. However, the current research is still weak, but there are many issues which still need further study and discussion. Future research can be carried out on the territory of the psychological from the following aspects.

First, Scholars should strengthen the meaning of psychological territory and structure of psychological territory in future research. Employees' psychological territory of organizational behavior is an emerging field of study, only a study of Brown and his colleagues on the psychological meaning and structure of the relevant employee is still in its infancy, particularly empirical research is still rare. In the future, cross-cultural study of employees' psychological territory would be a problem worthy of further exploration; research in the unique cultural connotation of China's special territory of the psychological background of the staff will help us have a deeper understanding of the organization of this unique phenomenon.

Second, the employee psychological studies are carried out from the territory of the individual, team and organizational levels. Employees' psychological territory may also be present in the team and organizational level. Most current scholars study the territory based on the individual level and this research is perfect; only Chu and Yang (2011) from the team try to study the level of employees' psychological territory of negative impact. Therefore, future research is necessary to expand from the individual level to the team, and even the organizational level [22].

Finally, expanding the territory of employee psychological antecedents, consequences empirical study variables. Currently, most research on the psychological territory of employees is qualitative analysis, mainly through simple interviews and behavioral observation to conclude that, while empirical research rarely, employee psychological territory of antecedents, consequences variables also need empirical research further proof. Possible future in-depth study on the impact of other factors of employees' psychological territory through empirical research, as well as the positive and negative impacts verify employees' psychological territory of the organization generated.

\section{References}

[1] Hu, S.M. (2005) Review of Job Insecurity. Advances in Psychological Science, 15, 938-947.

[2] Chen, X.H. (2009) Comprehensive Incentive Model: Let the Employees to Motivate Themselves. Human Resources, 1, $10-13$.

[3] Malmberg, T. (1980) Human Territoriality. Vol. 11, Mouton, New York, 31-35.

[4] Edney, J. (1974) Human Territoriality. Psychological Bulletin, 81, 959-973.

[5] Brown, G., Lawrence, T.B. and Robinson, S.L. (2005) Territoriality in Organizations. Academy of Management Review, 30, 577-594.

[6] Sack, R. (1986) Human Territoriality: Its Theory and History. Vol. 14, Cambridge University Press, Cambridge, 16-18.

[7] Brown, G. (2009) Claiming a Corner at Work: Measuring Employee Territoriality in Their Workspaces. Journal of Environmental Psychology, 29, 44-52.

[8] Brown, G. and Robinson, S.L. ( 2010) Reactions to Territorial Infringement. Organization Science, 22, $210-224$.

[9] Peng, H. (2012) Territorial Behaviors Research: An Emerging Area in Organizational Behavior. Economic Management Journal, 34, 182-189.

[10] Pierce, J.L., Linn, V.D. and Tatiana, K. (1995) Psychological Ownership: An Empirical Examination of Its Consequences. Group and Organization Management, 20, 210-226.

[11] Mercer, G.W. and Benjamin, M. (1980) Spatial Behavior of University Undergraduates in Double-Occupancy Residence Rooms: An Inventory of Effects. Journal of Applied Social Psychology, 10, 32-44. http://dx.doi.org/10.1111/j.1559-1816.1980.tb00691.x

[12] Wells, M.M. (2000) Office Clutter or Meaningful Personal Displays: The Role of Office Personalization in Employee and Organizational Well-Being. Journal of Environmental Psychology, 20, 239-255. http://dx.doi.org/10.1006/jevp.1999.0166

[13] Chu, X. and Ni, J. (2009) Forefront Research of the Organization Territoriality. Foreign Economics \& Management, 31, 18.

[14] Jarvenpaa, S. and Tanriverdi, H. (2006) Knowledge Ownership and Territoriality: A Conceptualization and ScenarioBased Experimental Investigation. Academy of Management Meeting, Atlanta, 11-16 August 2006, G1-G6.

[15] Altman, I. (1975) Environment and Social Behavior: Privacy, Personal Space, Territory, and Crowding. Brooks/Cole, 
Monterey.

[16] Jehn, K.A. (1997) A Qualitative Analysis of Conflict Types and Dimensions in Organizational Groups. Administrative Science Quarterly, 42, 530-557. http://dx.doi.org/10.2307/2393737

[17] Jehn, K.A., Northcraft, G.B. and Neale, M.A. (1999) Why Differences Make a Difference: A Field Study of Diversity, Conflict, and Performance in Workgroups. Administrative Science Quarterly, 44, 741-763. http://dx.doi.org/10.2307/2667054

[18] Jehn, K.A. (1992) The Impact of Intragroup Conflict on Effectiveness: A Multi-Method Examination of the Benefits and Detriments of Conflict. Unpublished Doctoral Dissertation, Northwestern University, USA.

[19] Peng, H. (2011) To Share or Hoard: Knowledge-Based Psychological Ownership, Territoriality and Knowledge-Hoarding. Academy of Management Annual Meeting, San Antonio, 12-16 August 2011, 67-68.

[20] Webster, J., Brown, G., Zweig, D., Connelly, C.E., Brodt, S. and Sitkin, S. (2008) Beyond Knowledge Sharing: Withholding Knowledge at Work. In: Research in Personnel and Human Resources Management, Vol. 27, 1-37. http://dx.doi.org/10.1016/S0742-7301(08)27001-5

[21] Brown, G. and Robinson, S.L. (2007) The Dysfunction of Territoriality in Organizations. Research Companion to the Dysfunctional Workplace: Management Challenges and Symptoms, 252. http://dx.doi.org/10.4337/9781847207081.00023

[22] Chu, X.P. and Yang, X.F. (2011) Analysis of Individual and Team Levels: The Negative Impact of Employees' Psychological Territoriality. Journal of Sun Yat-Sen University, 5, 161-168.

[23] Nohria, N., Boris, Linda and Eling (2008) Employee Motivation Four Forces Model. Harvard Business Review, 8, 8894. 
Scientific Research Publishing (SCIRP) is one of the largest Open Access journal publishers. It is currently publishing more than 200 open access, online, peer-reviewed journals covering a wide range of academic disciplines. SCIRP serves the worldwide academic communities and contributes to the progress and application of science with its publication.

Other selected journals from SCIRP are listed as below. Submit your manuscript to us via either submit@scirp.org or Online Submission Portal.
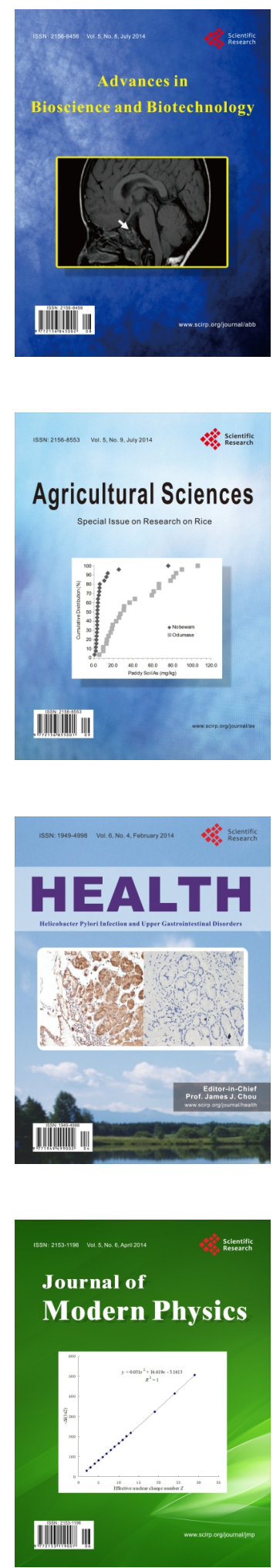
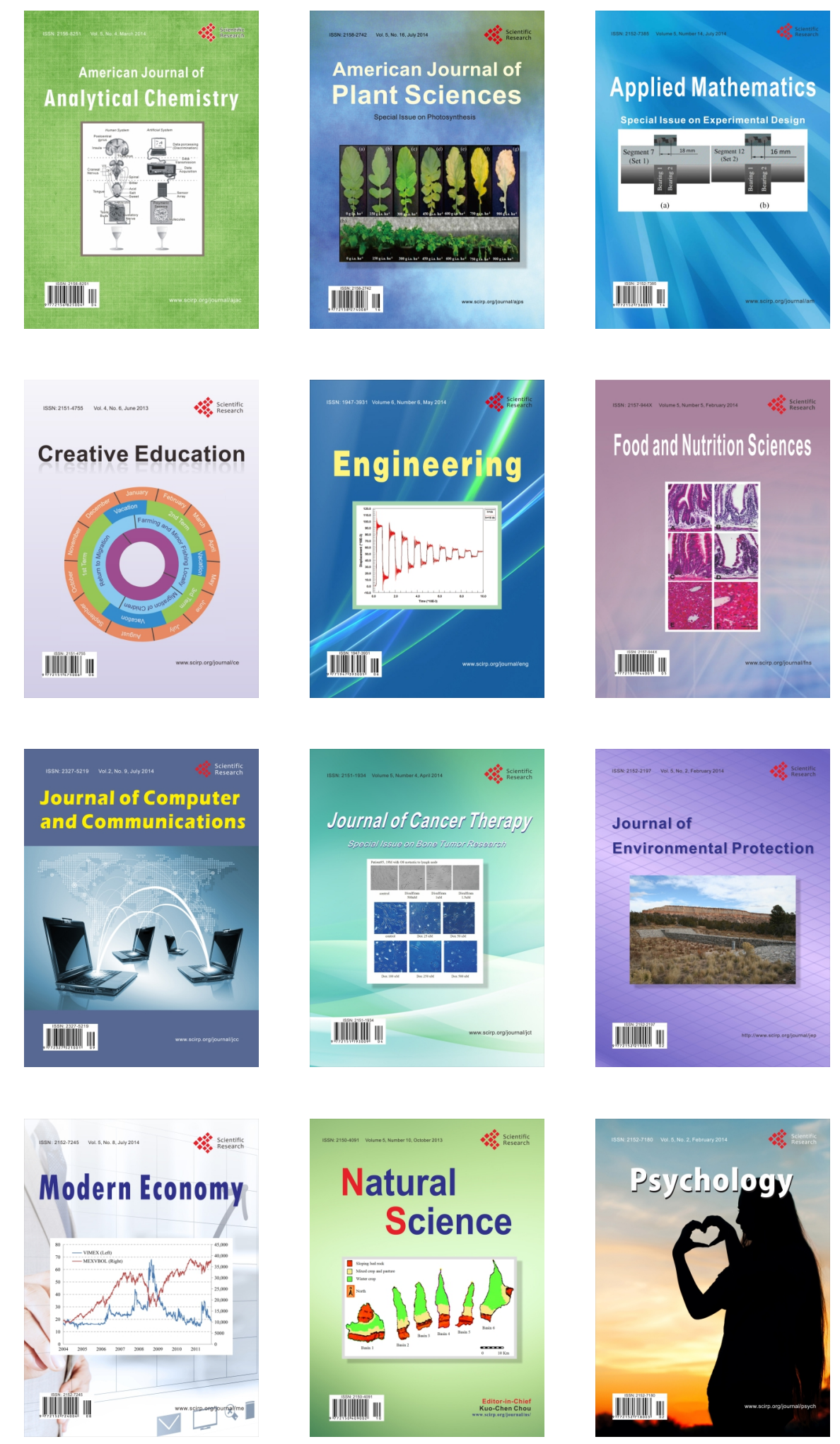